Supporting Information:

Uncompetitive Antagonism of AMPA Receptors: Mechanistic Insights from Studies of Polyamine Toxin Derivatives

Trine F. Andersen, ${ }^{\dagger}$ Denis B. Tikhonov, ${ }^{\ddagger}$ Ulrik Bølcho, ${ }^{\#}$ Konstantin Bolshakov, ${ }^{\ddagger}$, Jared K. Nelson, ${ }^{\dagger}$ Florentina Pluteanu, ${ }^{\natural}$ Ian R. Mellor, "Jan Egebjerg, ${ }^{\#, \S}$ Kristian Strømgaard ${ }^{\dagger, *}$

${ }^{\dagger}$ Department of Medicinal Chemistry, The Danish University of Pharmaceutical Sciences DK-2100 Copenhagen, Denmark, ${ }^{\ddagger}$ Sechenov Institute of Evolutionary Physiology and Biochemistry, Russian Academy of Sciences, St. Petersburg 194223, Russia, "Department for Molecular Biology, University of Aarhus, DK-8000 Aarhus, Denmark, "Division of Molecular Toxicology, School of Biology, University of Nottingham, Nottingham NG7 2RD, United Kingdom, ${ }^{\S}$ Division of Molecular Biology, H. Lundbeck A/S, DK-2500 Valby, Denmark

*E-mail:krst@dfuni.dk 


\section{Biological results}

Table 1. Biological results of PhTX-5n analogs

\begin{tabular}{lccc}
\hline & & & \\
& $n$ & $12.33 \pm 1.47(4)$ & $K_{i}(\mu \mathrm{M})^{b}$ \\
\hline $\mathbf{1 0 a}$ & 2 & $1.10 \pm 0.20(5)$ & $0.410 \pm 0.030$ \\
$\mathbf{1 0 b}$ & 3 & $0.283 \pm 0.039(4-11)$ & $0.063 \pm 0.022$ \\
$\mathbf{1 0}$ & 5 & $0.087 \pm 0.009(3-12)$ & $0.068 \pm 0.018$ \\
$\mathbf{1 0 d}$ & 6 & $0.127 \pm 0.010(3-11)$ & $0.095 \pm 0.041$ \\
$\mathbf{4}$ & 7 & $0.160 \pm 0.015(3-8)$ & $0.020 \pm 0.006$ \\
$\mathbf{1 0 e}$ & 8 & $0.798 \pm 0.052(6-9)$ & $0.330 \pm 0.030$ \\
$\mathbf{1 0 f}$ & 9 & $\mathrm{NT}$ & $0.450 \pm 0.070$ \\
$\mathbf{1 0 g}$ & 10 & $\mathrm{NT}$ & $0.180 \pm 0.080$ \\
$\mathbf{1 0 h}$ & 12 & &
\end{tabular}

${ }^{a}$ Inhibition of the current elicited by $100 \mu \mathrm{M}$ kainate by simultaneous co-application of the philanthotoxin in oocytes injected with rat brain RNA. The numbers in parentheses are numbers of oocytes used for each philanthotoxin concentration.

${ }^{b}$ Inhibition of the current elicited by $100 \mu \mathrm{M}$ glutamate by simultaneous co-application of the antagonist in oocytes injected with GluR1 flop RNA. Values are means of two independent measurements performed in triplicate.

NT; not tested. 
Table 2. Biological results of PhTX-n6 analogs

\begin{tabular}{llll}
\hline & $0.310 \pm 0.036(5-6)$ & $K_{i}(\mu)^{b}$ \\
\hline $13 a$ & 2 & $0.547 \pm 0.117(4-12)$ & $0.208 \pm 0.103$ \\
$13 b$ & 3 & $0.324 \pm 0.067(5-8)$ & $0.126 \pm 0.037$ \\
$13 c$ & 4 & $0.087 \pm 0.009(3-12)$ & $0.053 \pm 0.011$ \\
4 & 5 & $0.270 \pm 0.043(7-9)$ & $0.020 \pm 0.006$ \\
$13 d$ & 7 & $0.045 \pm 0.028(3-17)$ & $0.685 \pm 0.204$ \\
$13 e$ & 8 & $0.025 \pm 0.003(9-14)$ & $0.077 \pm 0.022$ \\
$13 f$ & 9 & $0.086 \pm 0.008(8-13)$ & $0.037 \pm 0.010$ \\
$13 g$ & &
\end{tabular}

anhibition of the current elicited by $100 \mu \mathrm{M}$ kainate by simultaneous co-application of the philanthotoxin in oocytes injected with rat brain RNA. The numbers in parentheses are numbers of oocytes used for each philanthotoxin concentration.

${ }^{b}$ Inhibition of the current elicited by $100 \mu \mathrm{M}$ glutamate by simultaneous co-application of the antagonist in oocytes injected with GluR1 flop RNA. Values are means of two independent measurements performed in triplicate. 
Table 3. Biological results of PhTX-nm derivatives

\begin{tabular}{lllcl}
\hline & & & & \\
& $n$ & $m$ & $\mathrm{IC}_{50}(\mu \mathrm{M})^{\mathrm{a}}$ & \\
\hline $\mathbf{1 4 a}$ & 3 & 8 & $0.248 \pm 0.043(9)$ & $0.350 \pm 0.030$ \\
$\mathbf{1 4 b}$ & 4 & 7 & $0.016 \pm 0.002(4-8)$ & $0.038 \pm 0.004$ \\
$\mathbf{4}$ & 5 & 6 & $0.087 \pm 0.009(3-12)$ & $0.003 \pm 0.001$ \\
$\mathbf{1 4 c}$ & 6 & 5 & $0.388 \pm 0.037(4)$ & $0.468 \pm 0.035$ \\
$\mathbf{1 4 d}$ & 7 & 4 & $0.138 \pm 0.033(5)$ & $0.168 \pm 0.020$ \\
$\mathbf{3}$ & 8 & 3 & $0.039 \pm 0.006(4-12)$ & $0.065 \pm 0.020$ \\
$\mathbf{1 4 e}$ & 9 & 2 & $0.122 \pm 0.011(6)$ & $0.410 \pm 0.060$ \\
\hline
\end{tabular}

anhibition of the current elicited by $100 \mu \mathrm{M}$ kainate by simultaneous co-application of the philanthotoxin in oocytes injected with rat brain RNA. The numbers in parentheses are numbers of oocytes used for each philanthotoxin concentration.

${ }^{b}$ Data from Kroman et al. (J. Med. Chem. 2002, 45, 5745-5754). 
Table 4. Channel-blocking affinities $\left(K_{\mathrm{i}}\right)$ of PhTX-56 and derivatives on GluR1

Compound $\quad K_{\mathrm{i}}(\mu \mathrm{M})^{a}$

\begin{tabular}{lllll} 
& \multicolumn{1}{c}{$-60 \mathrm{mV}$} & $-80 \mathrm{mV}$ & $-100 \mathrm{mV}$ & $\delta \mathrm{z}$ \\
\hline $\mathbf{1 0 a}$ & $1.5 \pm 0.1$ & $0.41 \pm 0.03$ & $0.14 \pm 0.02$ & $1.50 \pm 0.08$ \\
$\mathbf{1 0 b}$ & $0.27 \pm 0.05$ & $0.063 \pm 0.022$ & $0.014 \pm 0.006$ & $1.87 \pm 0.02$ \\
\hline $10 \mathrm{c}$ & $0.45 \pm 0.05$ & $0.068 \pm 0.018$ & $0.013 \pm 0.003$ & $2.24 \pm 0.08$ \\
$\mathbf{1 0 d}$ & $0.46 \pm 0.07$ & $0.095 \pm 0.041$ & $0.013 \pm 0.005$ & $2.25 \pm 0.15$ \\
$\mathbf{4}$ & $0.66 \pm 0.19$ & $0.062 \pm 0.013$ & $0.010 \pm 0.003$ & $2.65 \pm 0.20$ \\
$\mathbf{1 0 e}$ & $1.1 \pm 0.1$ & $0.11 \pm 0.02$ & $0.010 \pm 0.002$ & $2.97 \pm 0.03$ \\
$\mathbf{1 0 f}$ & $2.3 \pm 0.2$ & $0.33 \pm 0.03$ & $0.037 \pm 0.012$ & $2.61 \pm 0.09$ \\
$\mathbf{1 0 g}$ & $5.0 \pm 0.9$ & $0.45 \pm 0.07$ & $0.065 \pm 0.011$ & $2.74 \pm 0.17$ \\
$\mathbf{1 0 h}$ & $1.2 \pm 0.1$ & $0.18 \pm 0.08$ & $0.026 \pm 0.007$ & $2.40 \pm 0.12$ \\
$\mathbf{1 0 i}$ & $3.1 \pm 0.3$ & $0.48 \pm 0.15$ & $0.077 \pm 0.023$ & $2.35 \pm 0.09$
\end{tabular}

IInhibition of the current elicited by $100 \mu \mathrm{M}$ glutamate by simultaneous co-application of the antagonist in oocytes injected with GluR1 flop RNA. Values are means of two independent measurements performed in triplicate. 